\title{
Effect of phosphogypsum and turkey litter on the erodibility of agrochernozems of the southern Cis-Ural (Russia) under artificial heavy rainfall
}

\author{
Ruslan Suleymanov ${ }^{1}$, Irik Saifullin'2, Mikhail Komissarov ${ }^{1 *}$, Ilyusya Gabbasova ${ }^{1}$, \\ Azamat Suleymanov ${ }^{I}$ and Timur Garipov ${ }^{l}$ \\ ${ }^{1}$ Ufa Institute of Biology UFRC, Russian Academy of Sciences, pr. Oktyabrya 69, Ufa, 450054, Russia \\ ${ }^{2}$ Bashkir State University, Zaki Validi 32, Ufa 450076, Russia
}

\begin{abstract}
In the present study, we evaluated the effects of surface application and plowing of phosphogypsum and turkey litter to a depth of $20 \mathrm{~cm}$ on the erodibility of clay-illuvial agrochernozem (Luvic Chernozems (Aric, Pachic)) in the Southern Cis-Urals (Republic of Bashkortostan, Russia). Under laboratory conditions, $1^{\circ}, 3^{\circ}$, and $7^{\circ}$ slopes were modeled. Soil loss, runoff onset time, and turbidity were measured with a rainfall simulator. Particle size distribution and total organic carbon were measured. Under simulated heavy rainfall (360-420 $\mathrm{mm} \mathrm{h}^{-1}$ ) for $30 \mathrm{~min}$, the untreated control had the highest soil loss $\left(28.9 \mathrm{th}^{-1}\right)$. Separate and combined introductions of phosphogypsum and turkey litter significantly increased soil resistance to water erosion. Co-introduction of the amendments strengthened this effect especially when the phosphogypsum to turkey litter ratio increased from 1:10 to 1:2 at the higher dose $\left(60 \mathrm{t} \mathrm{ha} \mathrm{h}^{-1}\right)$. The turbidity of the runoff from a $1^{\circ}$ slope reached a small peak within the first 3 min then gradually decreased thereafter. At $3^{\circ}$, the turbidity remained nearly constant over time and was uniformly distributed. At $7^{\circ}$, the turbidity sharply increased then gradually decreased and its distribution was a deformed bell. Washed-out (trapped) sediments from all treatments and slopes had relatively more very fine sand, silt, and clay and a slightly higher total organic carbon content than the original soil. Phosphogypsum and turkey litter wastes may be effective anti-erosion amendments and potential fertilizers because they increase flocculation, improve the structure, and enrich the organic matter and nutrient content of the soil.
\end{abstract}

Keywords: Sprinkling, modeling, turkey litter, phosphogypsum, erosion

\section{Introduction}

Erosion is a major type of soil degradation which occurs worldwide (Ali et al., 2006; Khan et al., 2013; Addis and Klik, 2015; Golmohammadi et al., 2017). In Russia, erosion is also common (Golosov et al., 2011; Krasilnikov et al., 2013; Litvin et al., 2017; Golosov et al., 2018; Gusarov et al., 2018) especially in the central regions such as the Republic of Bashkortostan (RB) (Sobol et al., 2015). The RB is located between the Volga River and the Ural Mountains and active soil water erosion occurs there. About $64 \%$ of the agricultural land in the RB is already eroded. The high organizational, economic, agrotechnical, forestry, and hydrotechnical costs of reclamation in this region are incentives to seek alternative erosion remediation methods.

Pork manure (Barbosa et al., 2015), sheep manure (Gholami et al., 2016), and turkey litter (TL) (Costa et al., 2008) have been used to reduce top soil erosion and increase crop yield (Adeli et al., 2017). Certain polymers and structure-building amendments such as polyacrylamide (PAM) (Tang et al., 2006; Abu-Hamdeh et al., 2018) and gypsum or phosphogypsum (PG) (Cochrane et al., 2005;
Mamedov et al., 2010) also increase soil resistance to erosion. PG is calcium sulfate hydrate, a by-product of fertilizer production from phosphate rock. It consists mainly of gypsum $\left(\mathrm{CaSO}_{4} \cdot 2 \mathrm{H}_{2} \mathrm{O}\right)$. In central Russia (Saratov Oblast; near RB), PG is used to reduce deflation and water erosion (Belobrov et al., 2018). In Brazil, the introduction of TL $\left(1,200-4,800 \mathrm{~kg} \mathrm{ha}^{-1}\right)$ into red ferralitic soil (Dystrophic Red Latosols (Oxisols)) improved aggregation and increased aggregate water resistance especially in the 0 $20 \mathrm{~cm}$ layer (Costa et al., 2008).

The use of PAM during irrigation improves aggregate water resistance and soil infiltration capacity (Sepaskhah and Shahabizad, 2010). When PAM was added to irrigation water at the rate of $1 \mathrm{~kg} 100 \mathrm{~m}^{-3} \mathrm{ha}^{-1}$, runoff and soil loss decreased by 70-75\% compared with the control (Aase et al., 1998). When PAM was added to furrows, the surface runoff decreased by $94 \%$ relative to the untreated one (Sojka et al., 1998).

Gypsum and PG amendments reduce surface runoff because they flocculate soil particles during rainfall or irrigation. The anti-erosion effect of gypsum is related to its

\footnotetext{
*Email: mkomissarov@list.ru
} 
ability to flocculate dispersed soil colloids, and it is stronger in PG than gypsum. The former dissolves faster and produces higher calcium concentrations in the soil solution than the latter during rainfall or irrigation (Keren and Shainberg, 1981). In the southern steppe of the Ukraine, the introduction of PG into dark chestnut soil (Haplic Kastanozems) reduced its density, lowered its silt content, promoted aggregation, and increased its humic content (Martynenko, 2014).

Recently, the practice of applying fertilizers consisting of agroindustrial and woodworking waste (Gabbasova et al., 2007; Amin, 2018) and PG has become widespread (Hentati et al., 2015; Kammoun et al., 2017; Rakhimova et al., 2017). The use of PG alone or in combination with organic additives improves the physical and hydrological properties of the soil, delays runoff generation, and reduces the severity of water erosion.

To the best of our knowledge, this study is the first to test the efficacy of the PG-organic waste combination on water erosion mitigation in the RB. There are several reasons why this region is suitable for this particular research: 1) The RB region is characterized by a highly heterogeneous topography. Most of its agricultural land is situated on slopes of varying steepness (Gabbasova et al., 2016) and the soil can be easily washed out during water erosion, 2) The climate of the region is continental with severe, snowy winters, deep soil freezing, and frequent onset of soil erosion during spring thaw (Komissarov and Gabbasova, 2014), 3) Up to 37.3\% of the annual precipitation in the southern Urals contributes to soil erosion (Sobol et al., 2015), 4) Slopes irrigated by sprinkler in this region are susceptible to erosion. Sprinkling is the most common type of irrigation in the RB (Komissarov and Gabbasova, 2017), 5) In Russia and the RB, poultry farming is intensifying and generating thousands of tons of underutilized litter every year (Rusakova and Eskov, 2015), 6) In Russia and the RB, mineral fertilizer factories producing various chemicals based on apatite and sulfur pyrite generate $\sim 500,000$ tons of PG annually. Currently, > 10,000,000 tons of PG have been dumped in the RB. PG was traditionally used in the region to reclaim saline soils, solonets, and technogenic saline lands (Gabbasova and Suleimanov, 2007; Gabbasova et al., 2013), 7) There are large, readily accessible turkey farms and PG dumps in the Meleuz district of RB.

Whereas field research is usually long-term, simulations may accelerate data acquisition. For example, rainfall simulators have already proven to be effective in soil erosion studies (Aziz and Liatim, 2018; Polykov et al., 2018; Mhaske et al., 2019). The purposes of this study were to evaluate the resistance of agrochernozems to water erosion and determine the stabilization efficacy of PG and TL and their combination on model slopes of varying steepness using a small laboratory-scale rainfall simulator.

In view of climate change and increasing erosion in the RB (Sobol et al., 2015), our approach may establish the feasibility of using the abundant, cheap, underutilized local farm and mining wastes as soil anti-erosion amendments there. This practice has multiple benefits: it can (a) reduce the amount of industrial waste from factories; (b) help decrease soil erosion; (c) improve soil fertility and crop productivity; (d) prolong the useful life and improve the quality of existing arable land; and (e) help ensure and maintain food security.

\section{Materials and Methods}

The field study was conducted in the Ufimsky district of the RB (54 $50^{\prime} 23^{\prime \prime} \mathrm{N}, 55^{\circ} 44^{\prime} 55^{\prime \prime} \mathrm{E} ; 170 \mathrm{~m}$ a.s.1.). The arable horizon $(0-20 \mathrm{~cm})$ of a clay-illuvial, medium-eroded agrochernozem (Luvic Chernozems (Aric, Pachic)) formed on alluvial-diluvial carbonate parent material was studied. This soil type is the most common in the Southern Cis-Ural region and $>70 \%$ of it lies on slopes of $1-7^{\circ}$ (Gabbasova et al., 2016).

The PG and TL were brought to the study area from the factories of the Meleuz district of the RB. According to laboratory analyses, PG contained $\sim 87 \%$ gypsum. TL was disinfected with "PX-Ornikill" (Killgerm Chemicals Ltd., Ossett, UK), and PG and TL were mixed in a tank. Then these ameliorants were added to surface of the soil on a gently inclined $\left(3-5^{\circ}\right)$ slope with a northern exposure according to the following scheme:

1. Control (no PG or TL (C);

2. PG, $5 \mathrm{t} \mathrm{ha}^{-1}$ (PG-5);

3. PG, $10 \mathrm{t} \mathrm{ha}^{-1}$ (PG-10);

4. PG, $20 \mathrm{t} \mathrm{ha}^{-1}(\mathrm{PG}-20)$;

5. PG+TL, 1:10, $40 \mathrm{t} \mathrm{ha}^{-1}$ (PG+TL-40 (1:10));

6. PG+TL, 1:10, $60 \mathrm{t} \mathrm{ha}^{-1}$ (PG+TL-60 (1:10));

7. PG+TL, 1:5, $40 \mathrm{t} \mathrm{ha}^{-1}$ (PG+TL-40 (1:5));

8. PG+TL, 1:5, $60 \mathrm{t} \mathrm{ha}^{-1}$ (PG+TL-60 (1:5));

9. PG+TL, 1:2, $40 \mathrm{t} \mathrm{ha}^{-1}$ (PG+TL-40 (1:2));

10. PG+TL, 1:2, $60 \mathrm{t} \mathrm{ha}^{-1}$ (PG+TL-60 (1:2));

11. TL, $40 \mathrm{t} \mathrm{ha}^{-1}$ (TL-40);

12. TL, $60 \mathrm{t} \mathrm{ha}^{-1}$ (TL-60). 
To ensure uniform mixing of PG and TL, the soil was plowed to a depth of $20 \mathrm{~cm}$ with a two-wheel tractor. One year after moldboard-plowing and PG and TL supplementation, the undisturbed soil monoliths were accurately excavated, and placed in polypropylene trays ( $\mathrm{L}$ $=1.0 \mathrm{~m}, \mathrm{~W}=0.2 \mathrm{~m}, \mathrm{H}=0.15 \mathrm{~m}$ ) for the subsequent laboratory experiments. The soil in the trays was air-dried (to hygroscopic water at $10 \%$ moisture by weight) and used to assess the effects of artificial sprinkling on the induction of water erosion using a rainfall simulator (Figure 1). Technical details of the simulator and procedure are described in Sobol et al. (2017). Irrigation was performed at a rain intensity of $360-420 \mathrm{~mm} \mathrm{~h}^{-1}$ which is considered heavy (> $2.0 \mathrm{~mm} \mathrm{~min}^{-1}$ ) according to Kiryushin (1996). The total irrigation time was 33-45 min depending on the onset of runoff. The intensity and duration of sprinkling used in this study enabled monitoring of the dynamics of erosion development over time (Znamenskaya et al., 2018). Soil trays were irrigated on slopes of $1^{\circ}, 3^{\circ}$, and $7^{\circ}$ because these are the most common inclinations in the region (gentle, declivous, and aslant-steep, respectively).

The time of appearance of surface runoff after the start of irrigation was evaluated in this experiment. Fluid samples were taken at $0,3,5,8,15$, and $30 \mathrm{~min}$ after the onset of runoff to measure the amount of suspended sediment in the flow (turbidity). The runoff samples (trapped sediments) during irrigation were transported to a special reservoir fitted with absorbent paper. The sediments on the filters were air-dried to constant mass and weighed, and total soil losses were calculated (Surmach, 1976). Particle size distributions in the original soil and sediment samples were measured by gravitational sedimentation (pipette method). Total organic carbon (TOC) was determined by thermochemical oxidation with $\mathrm{K}_{2} \mathrm{Cr}_{2} \mathrm{O}_{7}$.

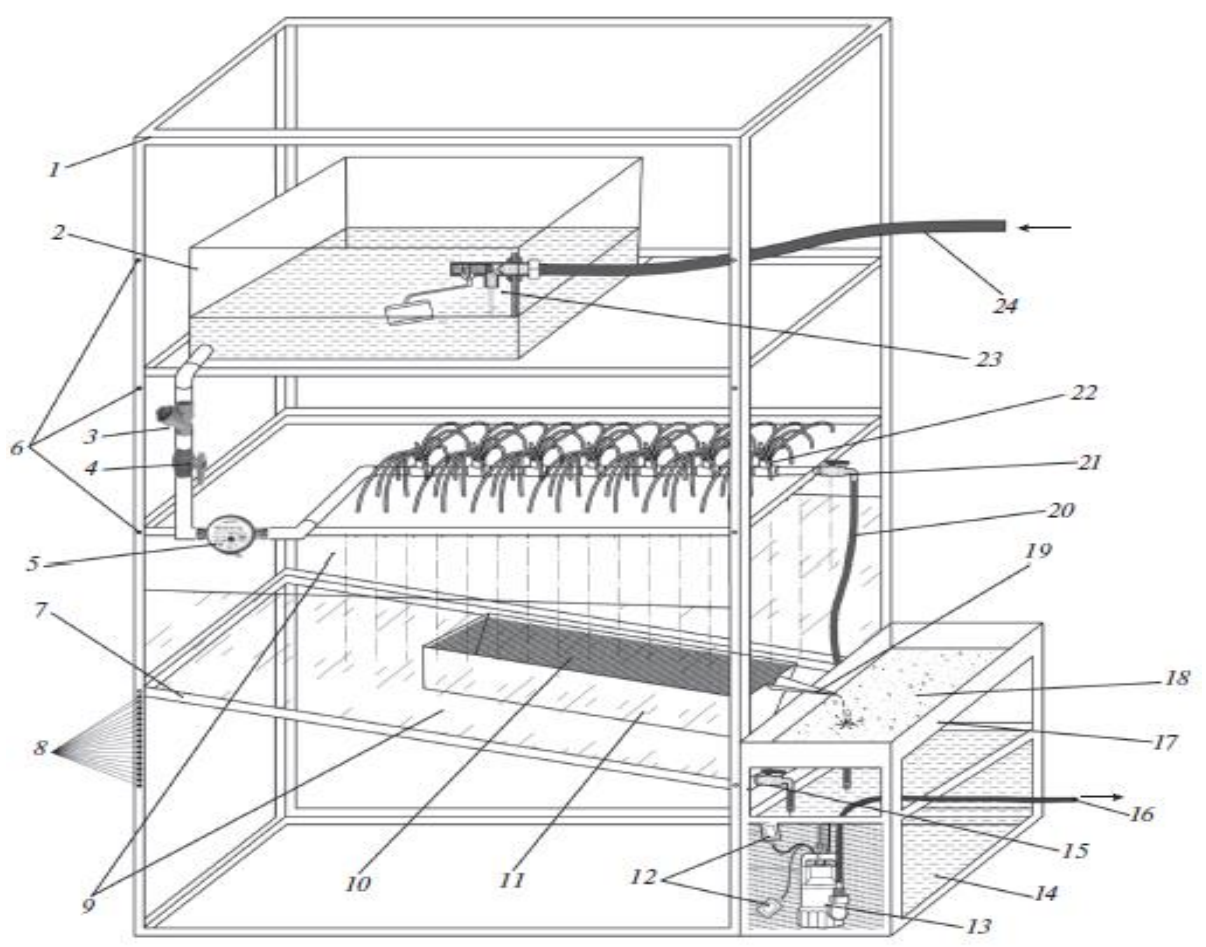

Figure 1: Sprinkler installation diagram

(1) frame; (2) reservoir; (3) filter; (4) water supply and valve; (5) flow meter; (6) height adjustment holes $(0.5,1.0$, and $1.5 \mathrm{~m})$; (7) base for flume with soil; (8) slope adjustment holes $\left(0-15^{\circ}\right)$; (9) anti-splash screen; (10) irrigated soil; (11) plastic flume (length $100 \mathrm{~cm}$, width $20 \mathrm{~cm}$, height $12 \mathrm{~cm}$ ); (12) switch with float sensor; (13) submersible pump; (14) runoff reservoir; (15) water discharge hole; (16) drainage hose; (17) collection tray with filter; (18) filter; (19) discharge trough; (20) water discharge hose; (21) drain valve; (22) sprinkler frame; (23) float valve; (24) water supply intake hose (Sobol et al., 2017) 
Field soil sampling, rainfall experiments, and laboratory analyses were conducted in triplicate. The data were averaged and reported in tables and graphs. All data were processed in MS Excel 2007 (v. 12.0) (Microsoft Corp., Redmond, WA, USA). Significance of the differences between means was estimated by a $t$-test.

Table 1. TOC and particle size distribution of original soil $(0-20 \mathrm{~cm}$ depth) and sediment (depending on the tray tilt angle)

\begin{tabular}{|c|c|c|c|c|c|c|c|}
\hline \multirow[t]{2}{*}{ Variant } & \multirow{2}{*}{$\begin{array}{c}\text { TOC } \\
\%\end{array}$} & \multicolumn{6}{|c|}{ Fraction size $(\mathrm{mm})$ and name } \\
\hline & & $\begin{array}{c}1-0.25 \\
\text { (coarse } \\
\text { sand) }\end{array}$ & $\begin{array}{l}0.25-0.05 \\
\text { (fine } \\
\text { sand) }\end{array}$ & $\begin{array}{l}0.05-0.01 \\
\text { (very fine } \\
\text { sand) }\end{array}$ & $\begin{array}{c}\text { 0.01-0.005 } \\
\text { (medium } \\
\text { silt) }\end{array}$ & $\begin{array}{c}0.005-0.001 \\
\text { (very fine } \\
\text { silt) }\end{array}$ & $\begin{array}{c}<0.001 \\
\text { (clay) }\end{array}$ \\
\hline & & \multicolumn{6}{|c|}{ Content $\%$} \\
\hline Original slope soil & $3.6 \pm 0.1$ & $7.5 \pm 0.4$ & $12.8 \pm 0.8$ & $16.9 \pm 0.7$ & $9.9 \pm 0.6$ & $23.8 \pm 1.4$ & $29.1 \pm 1.8$ \\
\hline \multicolumn{8}{|c|}{ Inclination $1^{\circ}$} \\
\hline 1. $\mathrm{C}$ & $4.0 \pm 0.2$ & $0.4 \pm 0.1$ & $3.1 \pm 0.2$ & $24.6 \pm 1.0$ & $7.0 \pm 0.6$ & $18.0 \pm 1.2$ & $46.9 \pm 2.5$ \\
\hline 2. PG-5 & $4.1 \pm 0.2$ & $1.9 \pm 0.1$ & $10.0 \pm 0.6$ & $20.1 \pm 0.7$ & $7.6 \pm 0.5$ & $12.4 \pm 0.6$ & $48.1 \pm 2.4$ \\
\hline 3. PG-10 & $4.0 \pm 0.1$ & $0.7 \pm 0.2$ & $9.6 \pm 0.4$ & $18.7 \pm 0.8$ & $9.1 \pm 0.7$ & $13.9 \pm 0.9$ & $47.9 \pm 2.4$ \\
\hline 4. $\mathrm{PG}-20$ & $4.1 \pm 0.1$ & $1.1 \pm 0.1$ & $7.5 \pm 0.5$ & $20.1 \pm 1.1$ & $10.4 \pm 0.9$ & $12.2 \pm 0.8$ & $48.8 \pm 3.1$ \\
\hline 5. PG+TL-40 (1:10) & $4.3 \pm 0.3$ & $0.5 \pm 0.1$ & $7.8 \pm 0.3$ & $22.3 \pm 0.6$ & $10.8 \pm 1.0$ & $13.3 \pm 0.8$ & $45.2 \pm 2.7$ \\
\hline 6. PG+TL-60 (1:10) & $4.4 \pm 0.2$ & $0.7 \pm 0.1$ & $7.8 \pm 0.3$ & $18.7 \pm 0.5$ & $10.5 \pm 0.8$ & $13.5 \pm 0.9$ & $48.9 \pm 2.6$ \\
\hline 7. PG+TL-40 (1:5) & $4.2 \pm 0.2$ & $0.3 \pm 0.1$ & $7.3 \pm 0.3$ & $20.2 \pm 0.9$ & $10.4 \pm 0.9$ & $13.7 \pm 1.1$ & $48.0 \pm 2.9$ \\
\hline 8. PG+TL-60 (1:5) & $4.2 \pm 0.3$ & $0.5 \pm 0.1$ & $8.7 \pm 0.4$ & $21.5 \pm 0.9$ & $8.7 \pm 0.8$ & $15.1 \pm 1.1$ & $45.6 \pm 3.0$ \\
\hline 9. PG+TL-40 (1:2) & $4.3 \pm 0.1$ & $1.1 \pm 0.1$ & $6.6 \pm 0.4$ & $20.6 \pm 0.9$ & $9.5 \pm 0.7$ & $12.8 \pm 1.0$ & $49.5 \pm 3.2$ \\
\hline 10. PG+TL-60 (1:2) & $4.4 \pm 0.2$ & $1.5 \pm 0.2$ & $7.6 \pm 0.2$ & $20.3 \pm 0.7$ & $9.7 \pm 0.8$ & $14.5 \pm 1.2$ & $46.4 \pm 2.8$ \\
\hline 11. TL-40 & $4.4 \pm 0.3$ & $1.2 \pm 0.1$ & $6.6 \pm 0.3$ & $18.3 \pm 0.7$ & $10.7 \pm 0.8$ & $14.3 \pm 0.9$ & $48.8 \pm 2.3$ \\
\hline 12. TL-60 & $4.2 \pm 0.1$ & $1.3 \pm 0.1$ & $5.3 \pm 0.3$ & $18.9 \pm 0.5$ & $11.3 \pm 10.6$ & $13.6 \pm 1.0$ & $49.6 \pm 2.6$ \\
\hline \multicolumn{8}{|c|}{ Inclination $3^{\circ}$} \\
\hline 1. $\mathrm{C}$ & $4.0 \pm 0.2$ & $0.6 \pm 0.2$ & $4.8 \pm 0.4$ & $22.5 \pm 0.8$ & $7.8 \pm 0.4$ & $18.5 \pm 1.2$ & $46.2 \pm 1.9$ \\
\hline 2. PG-5 & $3.9 \pm 0.2$ & $1.4 \pm 0.2$ & $9.4 \pm 0.3$ & $19.1 \pm 0.8$ & $9.2 \pm 0.5$ & $13.3 \pm 1.1$ & $47.7 \pm 2.7$ \\
\hline 3. PG-10 & $4.0 \pm 0.1$ & $0.7 \pm 0.2$ & $7.0 \pm 0.1$ & $21.3 \pm 0.9$ & $11.6 \pm 0.8$ & $11.1 \pm 0.8$ & $48.3 \pm 2.9$ \\
\hline 4. $\mathrm{PG}-20$ & $4.0 \pm 0.1$ & $0.4 \pm 0.1$ & $7.1 \pm 0.2$ & $20.8 \pm 0.8$ & $9.3 \pm 0.8$ & $11.5 \pm 1.2$ & $47.9 \pm 3.0$ \\
\hline 5. PG+TL-40 (1:10) & $4.2 \pm 0.1$ & $0.5 \pm 0.1$ & $9.3 \pm 0.2$ & $20.0 \pm 0.6$ & $8.7 \pm 0.5$ & $13.6 \pm 1.0$ & $47.9 \pm 2.9$ \\
\hline 6. PG+TL-60 (1:10) & $4.1 \pm 0.2$ & $0.9 \pm 0.1$ & $7.9 \pm 0.5$ & $20.1 \pm 0.7$ & $9.9 \pm 0.5$ & $14.3 \pm 0.8$ & $47.0 \pm 2.6$ \\
\hline 7. PG+TL-40 (1:5) & $4.2 \pm 0.1$ & $0.4 \pm 0.1$ & $9.3 \pm 0.6$ & $20.4 \pm 0.5$ & $8.2 \pm 0.6$ & $15.7 \pm 0.9$ & $46.0 \pm 2.5$ \\
\hline 8. PG+TL-60 (1:5) & $4.2 \pm 0.2$ & $0.3 \pm 0.1$ & $10.1 \pm 0.8$ & $19.5 \pm 0.6$ & $8.4 \pm 0.7$ & $15.4 \pm 1.3$ & $46.3 \pm 2.8$ \\
\hline 9. PG+TL-40 (1:2) & $4.2 \pm 0.2$ & $0.4 \pm 0.1$ & $9.1 \pm 0.5$ & $20.3 \pm 0.9$ & $8.9 \pm 0.6$ & $15.4 \pm 1.1$ & $46.0 \pm 2.7$ \\
\hline 10. PG+TL-60 (1:2) & $4.1 \pm 0.3$ & $1.0 \pm 0.1$ & $9.0 \pm 1.0$ & $19.0 \pm 0.7$ & $10.4 \pm 0.7$ & $15.3 \pm 1.0$ & $45.3 \pm 3.0$ \\
\hline 11. TL-40 & $4.0 \pm 0.3$ & $0.8 \pm 0.2$ & $7.0 \pm 0.6$ & $19.8 \pm 0.9$ & $11.4 \pm 0.7$ & $13.6 \pm 0.8$ & $47.5 \pm 2.7$ \\
\hline 12. TL-60 & $4.2 \pm 0.2$ & $0.9 \pm 0.1$ & $4.5 \pm 0.5$ & $18.5 \pm 0.7$ & $11.8 \pm 1.0$ & $14.9 \pm 1.0$ & $48.4 \pm 2.5$ \\
\hline \multicolumn{8}{|c|}{ Inclination $7^{\circ}$} \\
\hline 1. $\mathrm{C}$ & $3.9 \pm 0.3$ & $0.4 \pm 0.1$ & $3.6 \pm 0.3$ & $20.7 \pm 0.7$ & $10.2 \pm 0.6$ & $17.8 \pm 1.2$ & $47.3 \pm 2.9$ \\
\hline 2. PG-5 & $3.9 \pm 0.2$ & $1.1 \pm 0.3$ & $7.3 \pm 0.3$ & $20.6 \pm 1.2$ & $10.8 \pm 0.6$ & $15.2 \pm 1.2$ & $45.1 \pm 3.1$ \\
\hline 3. PG-10 & $4.0 \pm 0.2$ & $0.4 \pm 0.1$ & $8.5 \pm 0.3$ & $17.9 \pm 0.8$ & $12.7 \pm 0.8$ & $16.0 \pm 1.2$ & $44.8 \pm 3.1$ \\
\hline 4. $\mathrm{PG}-20$ & $4.0 \pm 0.2$ & $0.3 \pm 0.1$ & $6.0 \pm 0.2$ & $18.4 \pm 0.7$ & $11.8 \pm 0.8$ & $12.8 \pm 0.9$ & $46.8 \pm 3.0$ \\
\hline 5. PG+TL-40 (1:10) & $4.2 \pm 0.1$ & $0.2 \pm 0.1$ & $4.3 \pm 0.2$ & $20.9 \pm 0.8$ & $11.5 \pm 0.7$ & $15.6 \pm 1.0$ & $47.4 \pm 2.7$ \\
\hline 6. PG+TL-60 (1:10) & $4.2 \pm 0.3$ & $0.2 \pm 0.1$ & $5.1 \pm 0.3$ & $20.8 \pm 0.8$ & $10.6 \pm 0.4$ & $16.7 \pm 1.0$ & $46.7 \pm 2.8$ \\
\hline 7. PG+TL-40 (1:5) & $4.0 \pm 0.2$ & $0.4 \pm 0.2$ & $7.1 \pm 0.5$ & $20.2 \pm 0.8$ & $11.1 \pm 0.5$ & $16.5 \pm 0.8$ & $46.7 \pm 3.0$ \\
\hline 8. PG+TL-60 (1:5) & $4.0 \pm 0.1$ & $0.3 \pm 0.1$ & $4.8 \pm 0.4$ & $20.4 \pm 0.8$ & $10.0 \pm 0.5$ & $17.6 \pm 0.8$ & $46.9 \pm 3.3$ \\
\hline 9. PG+TL-40 (1:2) & $4.1 \pm 0.2$ & $0.8 \pm 0.1$ & $7.9 \pm 0.5$ & $19.0 \pm 0.7$ & $13.5 \pm 0.9$ & $14.7 \pm 0.8$ & $44.2 \pm 2.9$ \\
\hline 10. PG+TL-60 (1:2) & $4.1 \pm 0.4$ & $0.7 \pm 0.1$ & $7.9 \pm 0.7$ & $20.7 \pm 0.7$ & $9.8 \pm 0.8$ & $17.9 \pm 0.9$ & $44.2 \pm 3.1$ \\
\hline 11. TL-40 & $4.1 \pm 0.2$ & $0.2 \pm 0.1$ & $7.3 \pm 0.5$ & $19.9 \pm 0.6$ & $10.5 \pm 0.7$ & $16.5 \pm 0.8$ & $45.7 \pm 3.1$ \\
\hline 12. TL-60 & $4.1 \pm 0.3$ & $0.9 \pm 0.1$ & $5.2 \pm 0.5$ & $20.3 \pm 0.7$ & $11.3 \pm 0.6$ & $17.1 \pm 0.8$ & $47.1 \pm 3.2$ \\
\hline
\end{tabular}




\section{Results and Discussion}

Arable agrochernozems have an average TOC content of $\sim 3.6 \%$, weak-acid $\mathrm{pH}$, and 50-60 $\mathrm{cmol}$ (eq) $\mathrm{kg}^{-1}$ absorbed bases of which calcium predominates. Nutrient availability is generally high. These soils have an optimal density range of 1.1-1.2 $\mathrm{kg} \mathrm{m}^{-3}$ and a silty-clay-loam texture (Komissarov and Gabbasova, 2017) (Table 1). arrival of slope runoff is observed and it gradually decreases thereafter.

The turbidity of the runoff was $2-4.5 \times$ greater at a $3^{\circ}$ slope than it was at $1^{\circ}$ and the values remained nearly constant throughout the irrigation period. The turbidity dynamics gradually assumed a deformed bell distribution with increasing steepness up to $7^{\circ}$. The average turbidity during irrigation on all variants at $7^{\circ}$ slope was $9 x$ and $\sim 2 \times$

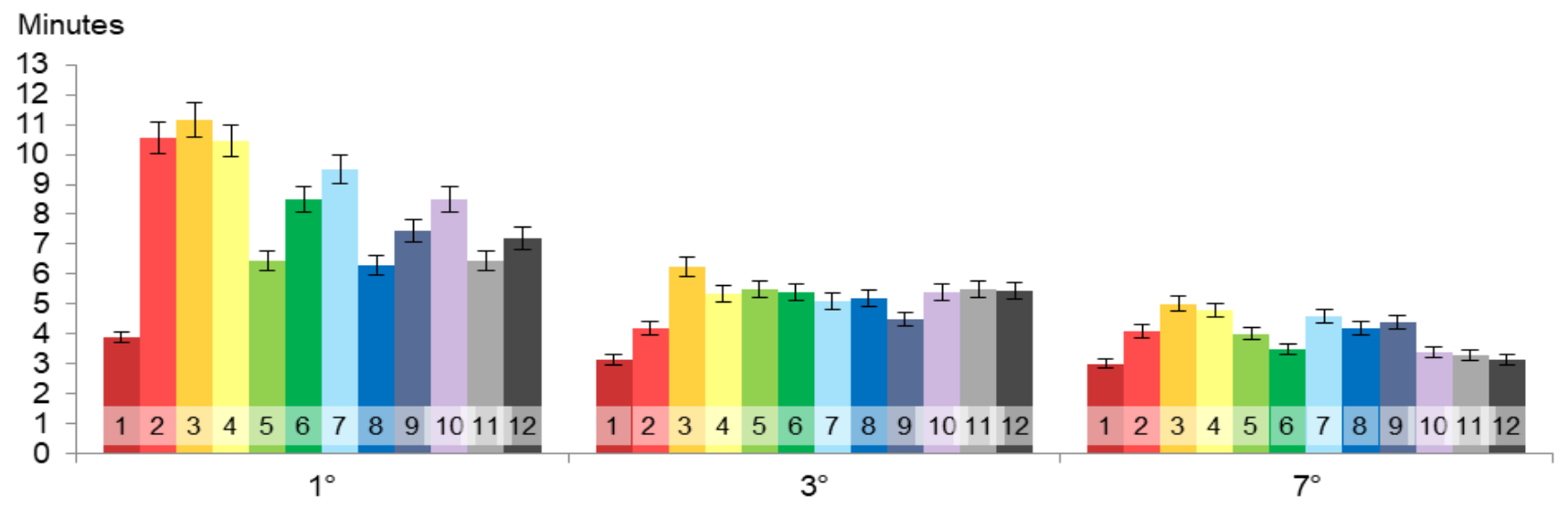

Figure 2: Time of appearance of surface runoff depending on angle of inclination and doses of FG and TL

Note: 1. C; 2. PG-5; 3. PG-10; 4. PG-20; 5. PG+TL-40 (1:10); 6. PG+TL-60 (1:10); 7. PG+TL-40 (1:5); 8. PG+TL-60 (1:5); 9. PG+TL40 (1:2); 10. PG+TL-60 (1:2); 11. TL-40; 12. TL-60

The most important indicators of the resistance of soils to water erosion are the onset time of runoff and total soil loss. Figure 2 shows that surface runoff first occurred in the control at all slopes. At $3^{\circ}$ and $7^{\circ}$, runoff started $\sim 1 \mathrm{~min}$ and $\sim 2$ min earlier than it did at $1^{\circ}$. The introduction of ameliorants delayed the onset of runoff by $65-186 \%$ at $1^{\circ}$, $33-98 \%$ at $3^{\circ}$, and $5-67 \%$ at $7^{\circ}$. Therefore, the onset time of runoff decreased with increasing slope. Higher anti-erosion resistance at all slopes was determined for the variants PG+TL-40 (1:2) and (1:5), and PG+TL-60 (1:5) and (1:10).

Turbidity depends on the number of suspended particles in the soil and can be used to elucidate the dynamics of rainfall erosion. Maximum stream turbidity was observed from the onset of runoff for $3 \mathrm{~min}$ on all $1^{\circ}$ slope variants. When the runoff started, the finest and loosest soil particles were detached and washed out first. Other researchers reported similar results for tray-based soil erosion experiments in which the first wave of the runoff was the most turbid (Grigor'ev et al., 2008; Larionov et al., 2016). Runoff turbidity then gradually decreased over the next 5-30 min (Table 2). For the $3^{\circ}$ and $7^{\circ}$ slope variants, the maximum water flow turbidity was measured at 3-5 min after the onset of runoff. At that time, the effect of the greater than it was at $1^{\circ}$ and $3^{\circ}$, respectively. The introduction of PG and TL into the soil at $3^{\circ}$ and $7^{\circ}$ slope decreased the level of stream turbidity, but it was nearly identical to that of the control. Thus, these amendments had only weak influences on the turbidity. In summary, the turbidity of the runoff from agrochernozem subjected to simulated heavy rain tended to increase with slope.

The soil loss was $2.3 \mathrm{t} \mathrm{ha}^{-1}$ for the control at a slope of $1^{\circ}$ (Figure 3 ). When the slope was increased to $3^{\circ}$, the soil loss increased by $4 \times$ and at $7^{\circ}$ it had increased by $10 \times$. The introduction of ameliorants reduced the sediment mass by 5-25\% for all slopes. The lowest sediment mass during irrigation at $1^{\circ}$ slope was measured for PG+TL-60 (1:5) and PG+TL-40 (1:2). However, the value for the latter variant was only slightly higher than that of the former. Very fine and medium silt particles $(0.005-0.001 \mathrm{~mm}$ and $0.05-0.01$ $\mathrm{mm}$, respectively) were washed out in these variants and the TOC in their sediments was $\sim 10 \%$ higher than that which was washed out of the control. The lowest soil losses at $3^{\circ}$ and $7^{\circ}$ slope were measured for PG+TL-60 (1:2) and PG+TL-40 (1:2). The mud fraction comprised the smallest proportion of the sediments in these variants. 
At $3^{\circ}$ and $7^{\circ}$, most of the particles washed out containing of very fine sand fractions. The TOC in the sediments washed out at $3^{\circ}$ was lower than that in the sediments washed out at $1^{\circ}$ because the flow rate and the movement of the humus- and nutrient-poor sand fraction increased with slope. Therefore, the lowest TOC was observed in sediments from the $7^{\circ}$ slope variants.
Relative to the control, in the sediments from all PG variants, the proportions of very fine silt and very fine sand decreased and increased, respectively, because of flocculation induced by PG. Compared with the control, the sand, silt, and clay content did not significantly change in the washed-out material fertilized with TL. Even in sediments, however, a slight increase in clay content is

Table 2. Changes in turbidity $\left(\mathrm{g} \mathrm{L}^{-1}\right)$ of runoff during heavy rains at different slopes

\begin{tabular}{|c|c|c|c|c|c|c|c|c|}
\hline \multirow[t]{2}{*}{ Variant } & \multirow[t]{2}{*}{ Slope, ${ }^{\circ}$} & \multicolumn{7}{|c|}{ Turbidity of runoff } \\
\hline & & $\begin{array}{c}\text { Runoff } \\
\text { start }\end{array}$ & $\begin{array}{l}3 \text { min from } \\
\text { runoff onset }\end{array}$ & $5 \mathrm{~min}$ & $8 \mathrm{~min}$ & $15 \mathrm{~min}$ & $30 \mathrm{~min}$ & Average \\
\hline \multirow[t]{3}{*}{ 1. $\mathrm{C}$} & 1 & $3.8 \pm 0.5$ & $2.7 \pm 0.4$ & $2.7 \pm 0.3$ & $1.3 \pm 0.1$ & $1.6 \pm 0.2$ & $1.1 \pm 0.1$ & 2.2 \\
\hline & 3 & $4.8 \pm 0.4$ & $11.7 \pm 0.5$ & $7.8 \pm 0.6$ & $7.0 \pm 0.4$ & $11.2 \pm 0.8$ & $10.5 \pm 1.2$ & 8.8 \\
\hline & 7 & $3.8 \pm 0.2$ & $30.8 \pm 0.8$ & $23.0 \pm 1.3$ & $21.1 \pm 1.4$ & $11.6 \pm 0.7$ & $8.8 \pm 0.7$ & 16.5 \\
\hline \multirow[t]{3}{*}{ 2. PG-5 } & 1 & $2.1 \pm 0.2$ & $1.3 \pm 0.1$ & $1.0 \pm 0.1$ & $0.9 \pm 0.2$ & $0.8 \pm 0.2$ & $0.7 \pm 0.2$ & 1.1 \\
\hline & 3 & $4.4 \pm 0.3$ & $9.1 \pm 0.6$ & $8.5 \pm 0.4$ & $8.3 \pm 0.4$ & $9.0 \pm 0.5$ & $7.7 \pm 0.9$ & 7.9 \\
\hline & 7 & $1.5 \pm 0.1$ & $26.4 \pm 1.0$ & $21.9 \pm 1.4$ & $14.2 \pm 1.0$ & $7.6 \pm 0.6$ & $9.2 \pm 1.0$ & 13.5 \\
\hline \multirow[t]{3}{*}{ 3. PG-10 } & 1 & $1.5 \pm 0.1$ & $1.4 \pm 0.2$ & $1.2 \pm 0.1$ & $1.1 \pm 0.2$ & $1.0 \pm 0.2$ & $1.1 \pm 0.3$ & 1.2 \\
\hline & 3 & $3.5 \pm 0.2$ & $6.9 \pm 0.5$ & $8.2 \pm 0.3$ & $7.9 \pm 0.5$ & $6.9 \pm 0.3$ & $6.9 \pm 0.8$ & 6.7 \\
\hline & 7 & $1.7 \pm 0.2$ & $17.8 \pm 0.7$ & $18.5 \pm 1.0$ & $13.8 \pm 0.7$ & $7.0 \pm 0.6$ & $5.5 \pm 0.7$ & 10.7 \\
\hline \multirow[t]{3}{*}{ 4. $\mathrm{PG}-20$} & 1 & $1.4 \pm 0.1$ & $1.5 \pm 0.3$ & $1.2 \pm 0.2$ & $1.0 \pm 0.1$ & $0.8 \pm 0.1$ & $0.8 \pm 0.2$ & 1.1 \\
\hline & 3 & $2.8 \pm 0.2$ & $4.6 \pm 0.5$ & $6.5 \pm 0.5$ & $6.8 \pm 0.4$ & $5.1 \pm 0.4$ & $6.4 \pm 0.6$ & 5.4 \\
\hline & 7 & $1.9 \pm 0.2$ & $12.4 \pm 0.8$ & $19.5 \pm 0.8$ & $11.9 \pm 0.8$ & $6.7 \pm 0.7$ & $6.5 \pm 0.8$ & 9.8 \\
\hline 5. PG+TL- & 1 & $1.5 \pm 0.1$ & $1.4 \pm 0.2$ & $1.2 \pm 0.2$ & $1.0 \pm 0.2$ & $0.9 \pm 0.2$ & $0.9 \pm 0.2$ & 1.2 \\
\hline \multirow[t]{2}{*}{$40(1: 10)$} & 3 & $2.8 \pm 0.3$ & $7.4 \pm 0.6$ & $7.7 \pm 0.6$ & $8.4 \pm 0.5$ & $8.6 \pm 0.5$ & $7.2 \pm 1.0$ & 7.0 \\
\hline & 7 & $3.0 \pm 0.4$ & $14.0 \pm 0.8$ & $14.1 \pm 0.9$ & $10.4 \pm 0.6$ & $18.4 \pm 1.1$ & $5.6 \pm 0.8$ & 10.9 \\
\hline 6. PG+TL- & 1 & $1.5 \pm 0.2$ & $1.1 \pm 0.2$ & $0.6 \pm 0.1$ & $0.7 \pm 0.1$ & $1.0 \pm 0.1$ & $1.7 \pm 0.3$ & 1.1 \\
\hline \multirow[t]{2}{*}{$60(1: 10)$} & 3 & $2.6 \pm 0.1$ & $7.7 \pm 0.6$ & $8.1 \pm 0.5$ & $7.9 \pm 0.9$ & $7.5 \pm 0.5$ & $7.0 \pm 0.5$ & 6.8 \\
\hline & 7 & $1.4 \pm 0.1$ & $15.9 \pm 0.6$ & $15.3 \pm 1.0$ & $8.5 \pm 0.9$ & $13.2 \pm 0.9$ & $8.6 \pm 0.8$ & 10.5 \\
\hline 7. PG+TL- & 1 & $1.7 \pm 0.2$ & $1.4 \pm 0.2$ & $1.3 \pm 0.3$ & $1.0 \pm 0.2$ & $0.9 \pm 0.1$ & $0.7 \pm 0.2$ & 1.2 \\
\hline \multirow[t]{2}{*}{$40(1: 5)$} & 3 & $2.7 \pm 0.2$ & $7.8 \pm 0.8$ & $8.2 \pm 0.4$ & $8.0 \pm 0.5$ & $7.9 \pm 0.9$ & $9.8 \pm 0.7$ & 7.4 \\
\hline & 7 & $1.6 \pm 0.1$ & $13.5 \pm 0.9$ & $16.4 \pm 0.9$ & $9.5 \pm 0.8$ & $9.3 \pm 1.0$ & $11.4 \pm 1.3$ & 10.3 \\
\hline 8. PG+TL- & 1 & $2.0 \pm 0.1$ & $1.0 \pm 0.1$ & $0.9 \pm 0.1$ & $1.7 \pm 0.1$ & $1.4 \pm 0.2$ & $1.2 \pm 0.2$ & 1.4 \\
\hline \multirow[t]{2}{*}{$60(1: 5)$} & 3 & $5.4 \pm 0.3$ & $10.9 \pm 0.3$ & $8.8 \pm 0.5$ & $6.1 \pm 0.8$ & $11.2 \pm 0.5$ & $7.9 \pm 0.6$ & 8.4 \\
\hline & 7 & $1.3 \pm 0.1$ & $12.7 \pm 0.7$ & $18.6 \pm 0.9$ & $13.5 \pm 1.0$ & $4.7 \pm 0.6$ & $4.8 \pm 0.5$ & 9.3 \\
\hline 9. PG+TL- & 1 & $1.2 \pm 0.2$ & $0.9 \pm 0.2$ & $0.9 \pm 0.2$ & $1.0 \pm 0.3$ & $0.8 \pm 0.2$ & $0.8 \pm 0.2$ & 0.9 \\
\hline \multirow[t]{2}{*}{$40(1: 2)$} & 3 & $3.5 \pm 0.2$ & $4.6 \pm 0.3$ & $7.5 \pm 0.7$ & $5.9 \pm 0.8$ & $6.2 \pm 0.5$ & $5.3 \pm 0.3$ & 5.5 \\
\hline & 7 & $1.3 \pm 0.1$ & $11.6 \pm 0.6$ & $13.0 \pm 0.8$ & $8.5 \pm 1.0$ & $7.2 \pm 0.7$ & $6.2 \pm 0.7$ & 8.0 \\
\hline 10. & 1 & $2.0 \pm 0.1$ & $1.6 \pm 0.1$ & $1.4 \pm 0.1$ & $1.0 \pm 0.1$ & $1.2 \pm 0.2$ & $1.0 \pm 0.1$ & 1.4 \\
\hline PG+TL-60 & 3 & $1.7 \pm 0.1$ & $7.1 \pm 0.5$ & $8.1 \pm 0.5$ & $9.8 \pm 0.6$ & $7.1 \pm 0.7$ & $10.0 \pm 0.7$ & 7.3 \\
\hline$(1: 2)$ & 7 & $1.6 \pm 0.1$ & $11.8 \pm 1.0$ & $12.9 \pm 0.8$ & $8.3 \pm 0.6$ & $8.4 \pm 0.9$ & $5.6 \pm 0.7$ & 8.1 \\
\hline \multirow[t]{3}{*}{ 11. TL-40 } & 1 & $1.6 \pm 0.1$ & $0.6 \pm 0.1$ & $0.9 \pm 0.1$ & $1.0 \pm 0.2$ & $1.0 \pm 0.1$ & $0.7 \pm 0.2$ & 1.0 \\
\hline & 3 & $3.0 \pm 0.3$ & $7.2 \pm 0.4$ & $7.8 \pm 0.9$ & $9.2 \pm 0.8$ & $8.1 \pm 0.6$ & $8.1 \pm 0.9$ & 7.2 \\
\hline & 7 & $3.6 \pm 0.2$ & $10.3 \pm 0.6$ & $20.0 \pm 1.3$ & $13.9 \pm 1.1$ & $9.8 \pm 1.0$ & $4.6 \pm 0.6$ & 10.4 \\
\hline \multirow[t]{3}{*}{ 12. TL-60 } & 1 & $1.5 \pm 0.1$ & $1.5 \pm 0.1$ & $0.9 \pm 0.2$ & $0.8 \pm 0.1$ & $0.9 \pm 0.2$ & $0.8 \pm 0.2$ & 1.1 \\
\hline & 3 & $2.0 \pm 0.2$ & $7.2 \pm 0.5$ & $8.1 \pm 0.9$ & $9.8 \pm 0.7$ & $7.9 \pm 0.7$ & $7.6 \pm 0.6$ & 7.1 \\
\hline & 7 & $1.6 \pm 0.1$ & $21.6 \pm 1.2$ & $22.1 \pm 1.4$ & $21.6 \pm 1.2$ & $8.9 \pm 0.9$ & $8.0 \pm 0.5$ & 14.0 \\
\hline
\end{tabular}

Note: for all variants, the differences between treatments and slopes in terms of turbidity at the beginning of runoff were insignificant. Three- to five minutes after the onset of runoff, the turbidity increased depending on the degree of the slope. It was significantly higher $(p<0.01)$ on $7^{\circ}(p<0.01)$ than on $3^{\circ}$ and significantly higher on $3^{\circ}(p<0.01)$ than on $1^{\circ}$. From 8 min onward, the relative differences in turbidity between the $3^{\circ}$ and $7^{\circ}$ slopes smoothed out and remained significantly higher than that for the $1^{\circ}$ slope. 
accompanied by a slight increase in organic matter. Erosion usually washes out the humus-rich silt and clay fractions (Sato and Kuwano, 2018; Nyawade et al., 2018).
Introduction of PG and TL separately or in combination significantly increased soil resistance to water erosion. All amendments reduced soil loss, but the lowest sediment

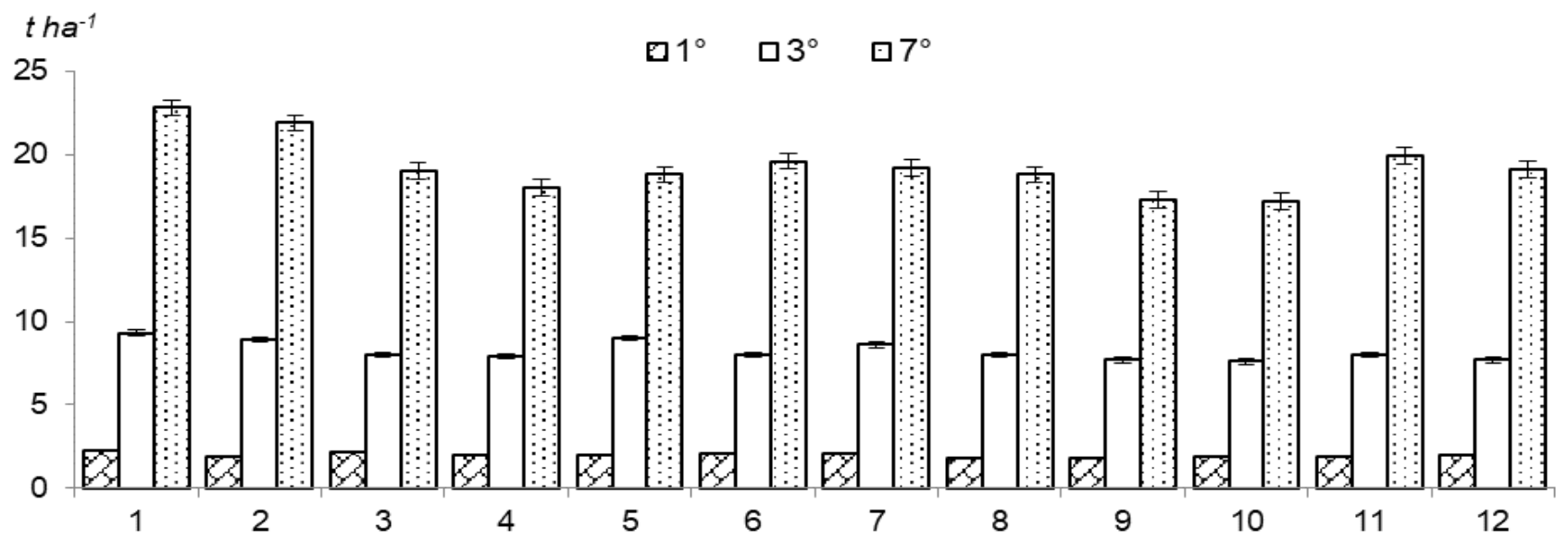

Figure 3: Soil losses on different slopes after artificial rainfall

Note: 1. C; 2. PG-5; 3. PG-10; 4. PG-20; 5. PG+TL-40 (1:10); 6. PG+TL-60 (1:10); 7. PG+TL-40 (1:5); 8. PG+TL-60 (1:5); 9. PG+TL40 (1:2); 10. PG+TL-60 (1:2); 11. TL-40; 12. TL-60

As stated in the Materials and Methods, we performed a three-year field study on the impact of PG and TL on agrochernozem properties and crop yields. This trial was conducted on the same slope as that where the monoliths were taken and used the same amendment variants as before. Previously, potatoes had been grown on the experimental plots. The addition of PG and TL increased yield by $14-120 \%$. The highest gains were determined for the TL variants at 40 and $60 \mathrm{t} \mathrm{ha}^{-1}$. The amendments also affected the hydrological and agrochemical properties of the soil in the arable $(0-20 \mathrm{~cm})$ layer. Relative to the control, the structure of the amended soil improved. The number of agronomically valuable and water-resistant aggregates increased. Bulk density decreased while air porosity and soil moisture content increased. The water level rose from 150 $\mathrm{mm}$ to $170 \mathrm{~mm}$. The TOC content increased from $3.6 \%$ to $4.2 \%$, and the nitrogen, phosphorus, and potassium levels also increased. The $\mathrm{pH}$ rose from weakly acidic to neutral. Therefore, the introduction of PG and TL into moderately eroded agrochernozem in the Southern Cis-Ural increased crop yield, improved soil properties, and reduced water erosion.

\section{Conclusion}

When an untreated agrochernozem was subjected to a simulated rain intensity of $360-420 \mathrm{~mm} \mathrm{~h}^{-1}$ (heavy rain), maximum soil loss was observed at the $7^{\circ}$ slope. It was $10 \times$ and $2.5 \times$ higher than those at $1^{\circ}$ and $3^{\circ}$, respectively. weights were determined for the PG:TL variants. This effect increased with ratio $(1: 10,1: 5,1: 2)$ when a higher ameliorant dose $\left(60 \mathrm{t} \mathrm{ha}^{-1}\right)$ was used. Regardless of steepness, the silt and clay fractions predominated in the sediment and their TOC content was somewhat higher than that of the soil before irrigation. Increasing the doses of PG at $1^{\circ}$ slope did not significantly affect runoff intensity. Increasing the steepness to $3^{\circ}$ incrementally raised erosion resistance. At $7^{\circ}$, however, runoff resistance decreased with PG dose. PG and TL could be effective agricultural soil amendments which could reduce the risk of water erosion and increase crop productivity.

\section{Acknowledgments}

This research was funded by a grant from the President of the Republic of Bashkortostan for young researchers (project name: "Assessment of the state of degraded lands in the Republic of Bashkortostan by the radiocesium method and development of organomineral fertilizers to improve soil fertility") and RFBR under project No. 18-34-00477.

\section{References}

Aase, J.K., D.L. Bjorneberg and R.E. Sojka. 1998. Sprinkler irrigation runoff and erosion control with polyacrylamide-laboratory tests. Soil Science Society of America Journal 62(6): 1681-1687.

Abu-Hamdeh, N.H., S.M. Ismail, S.G. Al-Solaimani and R.I. Hatamleh. 2018. Runoff and erosion as affected by 
tillage system and polyacrylamide in two sandy loam soils differing in silt and clay contents in semi-arid regions. Soil and Environment 37(1): 11-20.

Addis, H.K. and A. Klik. 2015. Predicting the spatial distribution of soil erodibility factor using USLE nomograph in an agricultural watershed, Ethiopia. International Soil and Water Conservation Research 3(4): 282-290.

Adeli, A., S.M. Dabney, H. Tewolde and J.N. Jenkins. 2017. Effects of tillage and broiler litter on crop productions in an eroded soil. Soil and Tillage Research 165: 198209.

Ali, I., F. Khan and A.U. Bhatti. 2006. Some physicochemical properties of soil as influenced by surface erosion under different cropping systems on upland-sloping soil. Soil and Environment 25(1): 2834.

Ali, M., F. Khan, Subhanullah, W. Ahmad., M. Ishaqand and M. Saeed. 2018. Enhancing wheat productivity and soil physical properties of water eroded agricultural land through integrated nutrient management. Soil and Environment 37(1): 21-27.

Amin, A.A. 2018. Improvement in phosphorus use efficiency of corn crop by amending the soil with sulfur and farmyard manure. Soil and Environment 37(1): 6267.

Aziz, M. and M. Liatim. 2018. The relations between the rainfall erosivity index AI and the hydraulics of overland flow and sediment concentration in sandy soils. Polish Journal of Soil Science 51(1): 41-58.

Barbosa, G.M.C., J.F. Oliveira, M. Miyazawa, D.B. Ruiz and F.J. Tavares. 2015. Aggregation and clay dispersion of an Oxisol treated with swine and poultry manures. Soil and Tillage Research 146: 279-285.

Belobrov, V.P., M.P. Lebedeva, K.N. Abrosimov, A.M. Grebennikov, E.L. Torochkov and A.I. Ryashko. 2018. Microdiagnostics of initial pedogenesis on a phosphogypsum dump. Spanish Journal of Soil Science 8(2): 183-193.

Cochrane, B.H.W., F.L.F. Eltz, L.D. Norton and J.M. Reichert. 2005. Controlling soil erosion and runoff with polyacrylamide and phosphogypsum on subtropical soil. Transactions of the American Society of Agricultural Engineers 48(1): 149-154.

Costa, A.M., B.T. Ribeiro, A.A. Silva and E.N. Borges. 2008. Aggregate stability of a Red Latosol amended with turkey litter. Ciencia e Agrotecnologia 32: 73-79. (in Portuguese with English abstract).

Gabbasova, I.M. and R.R. Suleimanov. 2007. Transformation of gray forest foils upon technogenic salinization and alkalization and subsequent rehabilitation in oil-producing regions of the southern Urals. Eurasian Soil Science 40: 1000-1007.

Gabbasova, I.M., R.R. Suleimanov, I.K. Khabirov, M.A. Komissarov, M. Frühauf, P. Liebelt, T.T. Garipov, L.V. Sidorova and F.H. Khaziev. 2016. Temporal changes of eroded soils depending on their agricultural use in the southern Cis-Ural region. Eurasian Soil Science 49(10): 1204-1210.

Gabbasova, I.M., R.R. Suleimanov, S.M. Dashkin and T.T. Garipov. 2007. Increasing the fertility of Trans-Ural steppe southern chernozems with the use of natural agricultural ores. Russian Agricultural Sciences 34(5): 325-328.

Gabbasova, I.M., R.R. Suleymanov and T.T. Garipov. 2013. Degradation and remediation of soils polluted with oilfield wastewater. Eurasian Soil Science 46(2): 204211.

Gholami, L., S.H.R. Sadeghi and M. Homaee. 2016. Different effects of sheep manure conditioner on runoff and soil loss components in eroded soil. Catena 139: 99-104.

Golmohammadi, G., R. Rudra, S. Prasher, A. Madani, M. Youssef, P. Goel and K. Mohammad. 2017. Impact of tile drainage on water budget and spatial distribution of sediment generating areas in an agricultural watershed. Agricultural Water Management 184: 124-134.

Golosov, V., O. Yermolaev, L. Litvin, N. Chizhikova, Z. Kiryukhina and G. Safina. 2018. Influence of climate and land use changes on recent trends of soil erosion rates within the Russian Plain. Land Degradation and Development 29(8): 2658-2667.

Golosov, V.N., A.N. Gennadiev, K.R. Olson, M.V. Markelov, A.P. Zhidkin, Yu.G. Chendev and R.G. Kovach. 2011. Spatial and temporal features of soil erosion in the forest-steppe zone of the East-European Plain. Eurasian Soil Science 44(7): 794-801.

Grigor'ev, V.Ya., M.S. Kuznetsov, D.R. Abdulkhanova and O.A. Bazarov. 2008. Calculation of parameters of soil particles detached and transported by shallow flows upon rill erosion. Eurasian Soil Science 41(3): 302311.

Gusarov, A.V., V.N. Golosov and A.G. Sharifullin. 2018. Contribution of climate and land cover changes to reduction in soil erosion rates within small cultivated catchments in the eastern part of the Russian Plain during the last 60 years. Environmental Research 167: 21-33.

Hentati, O., N. Abrantes, A.L. Caetano, S. Bouguerra, F. Goncalves, J. Römbke and R. Pereira. 2015. Phosphogypsum as a soil fertilizer: ecotoxicity of amended soil and elutriates to bacteria, invertebrates, 
algae and plants. Journal of Hazardous Materials 294: $80-89$.

Kammoun, M., I. Ghorbel, S. Charfeddine, L. Kamoun, R. Gargouri-Bouzid and O. Nouri-Ellouz. 2017. The positive effect of phosphogypsum supplemented composts on potato plant growth in the field and tuber yield. Journal of Environmental Management 20:475483.

Keren, R. and I. Shainberg. 1981. Effect of dissolution rate on the efficiency of industrial and mined gypsum in improving infiltration of a sodic soil. Soil Science Society of America Journal 45(1): 103-107.

Khan, F., Z. Hayat, W. Ahmad, M. Ramzan, Z. Shah, M. Sharif, I.A. Mian and M. Hanif. 2013. Effect of slope position on physicochemical properties of eroded soil. Soil and Environment 32: 22-28.

Kiryushin, V.I. 1996. The ecological basis of farming. Kolos, Moscow, 366 p. (in Russian).

Komissarov, M.A. and I.M. Gabbasova. 2017. Erosion of agrochernozems under sprinkler irrigation and rainfall simulation in the Southern forest-steppe of Bashkir CisUral region. Eurasian Soil Science 50(2): 253-261.

Komissarov, M.A. and I.M. Gabbasova. 2014. Snowmeltinduced soil erosion on gentle slopes in the Southern Cis-Ural region. Eurasian Soil Science 47(6): 598-607.

Krasilnikov, P., O. Makarov, I. Alyabina and F. Nachtergaele. 2016. Assessing soil degradation in northern Eurasia. Geoderma Regional 7(1): 1-10.

Larionov, G.A., O.G. Bushueva, N.G. Dobrovol'skaya, Z.P. Kiryukhina, L.F. Litvin, S.F. Krasnov. 2016. Assessing the contribution of nonhydraulic forces to the destruction of bonds between soil particles during water erosion. Eurasian Soil Science 49(5): 546-550.

Litvin, L.F., Z.P. Kiryukhina, S.F. Krasnov, and N.G. Dobrovol'skaya. 2017. Dynamics of agricultural soil erosion in European Russia. Eurasian Soil Science 50(11): 1344-1353.

Mamedov, A.I., I. Shainberg, L.E. Wagner, D.N. Warrington and G.J. Levy. 2010. Infiltration and erosion in soils treated with dry PAM, of two molecular weights, and phosphogypsum. Australian Journal of Soil Research 47(8): 788-795.

Martynenko, T.A. 2014. Agromeliorative efficiency of phosphogypsum under drip irrigation of mineralized waters in growing onion. Fertility 6: 41-43. (in Russian).

Mhaskea, S.N., K. Pathaka and A. Basak. 2018. A comprehensive design of rainfall simulator for the assessment of soil erosion in the laboratory. Catena 172: 408-420.

Nyawade, S., N. Karanja, C. Gachene, M. Parker and E. Schulte-Geldermann. 2018. Susceptibility of soil organic matter fractions to soil erosion under potatolegume intercropping systems in central Kenya. Journal of Soil and Water Conservation 73(6): 567-576.

Polyakov, V., J. Stone, C.H. Collins, M.A. Nearing, G. Paige, J. Buono and R.-L. Gomez-Pond. 2018. Rainfall simulation experiments in the southwestern USA using the Walnut Gulch Rainfall Simulator. Earth System Science Data 10: 19-26.

Rakhimova, A., A. Khussainov, I. Grinfelde. 2017. Impact of coal ash and phosphogypsum application on soil fertility of chernozem soils of north Kazakhstan. Latvia 2017: 16th International Scientific Conference Engineering for Rural Development: 1047-1051.

Rusakova, I.V. and A.I. Eskov. 2015. Effect of poultry manure in combination with straw on the biological properties of soddy-podzolic soil and the yielding capacity of grain crops. Russian Agricultural Sciences 41(5): 357-361.

Sato, M. and R. Kuwano. 2018. Laboratory testing for evaluation of the influence of a small degree of internal erosion on deformation and stiffness. Soils and Foundations 58: 47-562.

Sepaskhah, A.R. and V. Shahabizad. 2010. Effects of water quality and PAM application rate on the control of soil erosion, water infiltration and runoff for different soil textures measured in a rainfall simulator. Biosystems Engineering 106(4): 513-520.

Sobol, N.V., I.M. Gabbasova and M.A. Komissarov. 2015. Impact of climate changes on erosion processes in republic of Bashkortostan. Arid Ecosystems 5(4): 216221.

Sobol, N.V., I.M. Gabbasova and M.A. Komissarov. 2017. Effect of rainfall intensity and slope steepness on the development of soil erosion in the Southern Cis-Ural region (A model experiment). Eurasian Soil Science 50(9): 1098-1104.

Sojka, R.E., R.D. Lentz and D.T. Westermann. 1998. Water and erosion management with multiple applications of polyacrylamide in furrow irrigation. Soil Science Society of America Journal 62: 1672-1680.

Surmach, G.P. 1976. Water erosion and its control. Gidrometeoizdat, Leningrad, 254 p. (in Russian).

Tang, Z., T. Lei, J. Yu, I. Shainberg, A.I. Mamedov, M. Ben-Hur and G.J. Levy. 2006. Runoff and interrill erosion in sodic soils treated with dry PAM and phosphogypsum. Soil Science Society of America Journal 70: 679-690.

Znamenskaya, T.I., J.V. Vanteeva and S.V. Solodyankina. 2018. Factors of the development of water erosion in the zone of recreation activity in the Ol'khon region. Eurasian Soil Science 51(2): 221-228. 